\title{
Private Information and Insurance Rejections: A Comment*
}

\author{
Andrea Attar ${ }^{\dagger} \quad$ Thomas Mariotti ${ }^{\ddagger} \quad$ François Salanié ${ }^{\S}$
}

March 20, 2017

\begin{abstract}
We show that a necessary and sufficient condition for entry to be unprofitable in markets with adverse selection is that that no buyer type be willing to trade at a price above the expected unit cost of serving those types who are weakly more eager to trade than her. We provide two applications of this result. First, we characterize cases in which market breakdown occurs, thereby generalizing the main result of Hendren (2013). Second, we characterize entry-proof tariffs on nonexclusive active markets, thereby generalizing the main result of Glosten (1994). Our analysis paves the way to new tests of adverse selection, notably besides the case of inactive markets studied by Hendren (2013).
\end{abstract}

Keywords: Adverse Selection, Entry Proofness, Market Breakdown, Nonexclusivity. JEL Classification: D43, D82, D86.

*Financial support from the Chaire Marchés des Risques et Création de Valeur is gratefully acknowledged.

†Università degli Studi di Roma "Tor Vergata," Roma, Italy, and Toulouse School of Economics, CNRS, University of Toulouse Capitole, Toulouse, France.

$\ddagger$ Toulouse School of Economics, CNRS, University of Toulouse Capitole, Toulouse, France.

$\S$ Toulouse School of Economics, INRA, University of Toulouse Capitole, Toulouse, France. 


\section{Introduction}

In an important contribution, Hendren (2013) provides a necessary and sufficient condition for the breakdown of insurance markets subject to adverse selection. This condition extends that required for market unraveling in Akerlof (1970). Consider an insurer who attempts at entering an inactive insurance market, say by offering a small amount of coverage at a unit price $p$. Under adverse selection, the types of consumers who are the most eager to buy such coverage are also the most risky ones. Thus the insurer's offer attracts all consumers with risk above a certain threshold, and the corresponding expected cost to him can be computed as the upper-tail expectation of their risks. Overall, entry by a contract, or by a menu of such contracts, is unprofitable if and only if, for any consumer in a risk class, the willingness to pay at the no-trade point does not exceed this cost.

Hendren (2013) uses this no-trade condition to identify the relationship between adverse selection and insurance rejections in three nongroup markets: long-term care, disability, and life insurance. With reference to these markets, he concludes: "The most salient impact of private information may not be the adverse selection of existing contracts, but rather the existence of the insurance market" (Hendren (2013, page 1717)).

We show in this note that the relationship between the buyers' willingness to pay and the upper-tail expectations of unit costs yields a fundamental insight about the impact of adverse selection on market outcomes. To this end, we consider a general model of an adverse-selection economy in which little structure is put on buyers' preferences beyond the usual single-crossing condition. Our framework encompasses the insurance economies considered by Hendren (2013) — yet without assuming that consumers' preferences have an expected-utility representation, nor that there are only two possible loss levels - as well as standard trade environments, with and without wealth effects.

Our contribution is twofold.

First, we consider market breakdown. To evaluate the impact of adverse selection on feasible trades, we build on Wilson's (1993) demand-profile approach, and derive the expected profit on each additional marginal quantity in terms of the upper-tail expectation of the unit cost of serving those buyers who purchase this quantity. We employ this methodology in Theorem 1, which formulates a necessary and sufficient condition for the absence of any profitable trade in an inactive market. Corollary 1 applies this condition to characterize cases in which market breakdown occurs, the scenario considered in the quasilinear setting of Mailath and Nöldeke (2008), and in the insurance setting of Hendren (2013). We provide a unified treatment of these approaches, together with a comprehensive yet elementary proof. 
Our general analysis therefore calls for new applications of empirical tests on exclusion from trade in other environments in which adverse selection might be relevant, such as financial and labor markets.

Second, we argue that the above no-trade condition also sheds light on the impact of adverse selection on active markets. We consider nonexclusive markets, in which a seller cannot observe the offers that buyers receive from his competitors. ${ }^{1}$ Nonexclusivity makes screening a more difficult task, as any buyer can simultaneously purchase from several sellers, whereas her aggregate trades cannot be monitored. A seller may therefore find it optimal to limit the maximum quantity he stands ready to trade at any given price, so as to limit his losses with the most costly buyer types. In this situation, which corresponds to the actual working of limit-order markets, buyers face a convex market tariff, resulting from the convolution of the sellers' individual tariffs. The corresponding feasible allocations can then be described as those implementable by an entry-proof market tariff: a price-quantity schedule that prevents any profitable entry by a seller whose offers complement the existing ones (Glosten (1994)).

Our general approach delivers a full characterization of such entry-proof tariffs. We first observe that, from an entrant's viewpoint, everything happens as he were facing buyers whose preferences, for any given trade with the entrant, are represented by indirect utility functions incorporating their optimal trades along the market tariff. Convexity of the latter guarantees that these indirect utility functions inherit the regularity properties of the buyers' primitive utility functions. It is therefore a direct implication of our Theorem 1 that a tariff is entry-proof if and only if each buyer type's willingness to pay is at most equal to the corresponding upper-tail expectation of unit costs. In Corollary 2, we deduce from this that there exists a single budget-balanced allocation implementable by an entry-proof tariff, and essentially a single such tariff. This allocation corresponds to the allocation characterized, in different contexts, by Jaynes (1978), Hellwig (1988), and Glosten (1994). Our results quite significantly extend those of Glosten (1994), who restricts attention to quasilinear preferences, and suggest a direct way to evaluate the impact of adverse selection in nonexclusive financial and insurance markets, where wealth effects are likely to be relevant. In this regard, estimates of upper-tail expectations of unit costs may arguably become a key variable for future tests of adverse selection on active markets, complementing those developed by Hendren (2013) for inactive markets.

The paper is organized as follows. Section 2 describes the model. Section 3 states our

\footnotetext{
${ }^{1}$ Nonexclusive competition is a prominent feature of many financial and insurance markets. See Attar, Mariotti, and Salanié (2011, 2014, 2016a, 2016b) for illustrative examples.
} 
main result. Section 4 draws the implications of this result for market breakdown. Section 5 extends our analysis to active nonexclusive markets. Proofs not given in the text can be found in the appendices.

\section{The Economy}

Consider a buyer (she) endowed with private information, and whose type $i$ can take a finite number $I$ of values with positive probabilities $m_{i}{ }^{2}$ Type $i$ 's preferences are represented by a utility function $u_{i}(q, t)$ that is continuous and weakly quasiconcave in $(q, t)$ and strictly decreasing in $t$, with the interpretation that $q$ is the nonnegative quantity she buys and $t$ is the payment she makes in return. Types are ordered according to the single-crossing condition (Milgrom and Shannon (1994)), which states that higher types are weakly more eager to increase their purchases than lower types are:

For all $i<j, q<q^{\prime}, t$, and $t^{\prime}, u_{i}(q, t) \leq(<) u_{i}\left(q^{\prime}, t^{\prime}\right)$ implies $u_{j}(q, t) \leq(<) u_{j}\left(q^{\prime}, t^{\prime}\right)$.

To define marginal rates of substitution without supposing differentiability, let $\tau_{i}(q, t)$ be the supremum of the set of prices $p$ such that

$$
u_{i}(q, t)<\max \left\{u_{i}\left(q+q^{\prime}, t+p q^{\prime}\right): q^{\prime} \geq 0\right\} .
$$

Therefore, $\tau_{i}(q, t)$ is the slope of type $i$ 's indifference curve at the right of $(q, t)$. Weak quasiconcavity ensures that $\tau_{i}(q, t)$ is finite, except possibly when $q=0$, and that it is nonincreasing along an indifference curve of type $i$. We additionally make the intuitive assumption that, in the absence of transfers, a positive endowment of $q$ reduces this marginal rate of substitution.

Assumption 1 For all $i$ and $q>0, \tau_{i}(q, 0) \leq \tau_{i}(0,0)$.

Our assumptions on the buyer's preferences hold in a Rothschild and Stiglitz (1976) insurance economy, which is the case studied by Hendren (2013); then $i$ measures the buyer's riskiness, $q$ is the amount of coverage she purchases, and $t$ is the premium she pays in return. As we illustrate in Appendix A, they hold under several alternative specifications, allowing for multiple loss levels or various forms of nonexpected utility. Finally, they encompass a broad variety of other applications, such as financial and labor markets.

\footnotetext{
${ }^{2}$ The case of a seller can be handled thanks to a simple change of variables. In Appendix C, we prove that our results extend to arbitrary type distributions with bounded support over the real line. We refer to Mailath and Nöldeke (2008) for an exploration of the unbounded-support case.
} 
The supply side of the economy is represented by a linear technology, with unit cost $c_{i}>0$ when the buyer's type is $i$. For each $i$, we denote by $\bar{c}_{i}$ the upper-tail conditional expectation of unit costs,

$$
\bar{c}_{i} \equiv \mathbf{E}\left[c_{j} \mid j \geq i\right]=\frac{\sum_{j \geq i} m_{j} c_{j}}{\sum_{j \geq i} m_{j}} .
$$

In order to highlight the role of these expectations, we only require that $\bar{c}_{i}$ be nondecreasing in $i$. This is slightly more general than the usual definition of adverse selection, which states that unit $\operatorname{costs} c_{i}$ are nondecreasing in $i$. In fact, the monotonicity of $\bar{c}_{i}$ is exactly equivalent to the following condition, which we state for further reference:

$$
\text { For all } j<i, c_{j} \leq \bar{c}_{i} \text {. }
$$

\section{When Is an Inactive Market Entry-Proof?}

We say that a market is inactive when, for whichever reason, no trade takes place at all, so that each type $i$ has reservation utility $u_{i}(0,0)$. The question we address in this context is under which conditions an entrant (he) can profitably trade with the buyer.

Let us first analyze the case where the entrant offers a single contract, designed so as to attract a given type $i$. To do so, the entrant can choose some unit price $p$ slightly below $\tau_{i}(0,0)$. Then, by definition of $\tau_{i}(0,0)$, there exists a quantity $q$ that strictly attracts type $i$ at this price, that is, $u_{i}(q, p q)>u_{i}(0,0)$. As types are ordered according to the singlecrossing condition, we also have $u_{j}(q, p q)>u_{j}(0,0)$ for all $j>i$. Thus any type $j>i$ is strictly attracted as well, and the entrant bears an expected unit cost $\bar{c}_{i}$ when trading with types $j \geq i$. Finally, some types $j<i$ may also be attracted, but (1) ensures that this can only reduce the entrant's expected unit cost. This simple reasoning shows that the following no-entry (NE) property is necessarily satisfied if entry is unprofitable.

Property NE For each $i, \tau_{i}(0,0) \leq \bar{c}_{i}$.

Now, let us turn to the case where the entrant can offer a menu of contracts so as to screen the different buyer types. We say that an inactive market is entry-proof if there is no menu of contracts that yields the entrant a strictly positive expected profit no matter the buyer's best response. We already know from the above reasoning that Property NE is necessary for an inactive market to be entry-proof. The following result, for which a formal proof is provided in Appendix B, shows that it is also sufficient.

Theorem 1 An inactive market is entry-proof if and only if Property NE is satisfied. 
The key to the proof lies in the following remark. Suppose that the entrant offers an arbitrary menu of contracts. Under single crossing, a standard monotone-comparative-statics argument implies that the buyer has a best response with nondecreasing quantities; that is, the entrant ends up trading $\left(q_{i}, t_{i}\right)$ with each type $i$, with $q_{i} \leq q_{j}$ for all $i<j$. Then his expected profit is

$$
\sum_{i} m_{i}\left(t_{i}-c_{i} q_{i}\right)
$$

which, using a summation by parts, can be rewritten as:

$$
\sum_{i}\left(\sum_{j \geq i} m_{j}\right)\left[t_{i}-t_{i-1}-\bar{c}_{i}\left(q_{i}-q_{i-1}\right)\right],
$$

with $\left(q_{0}, t_{0}\right) \equiv(0,0)$ by convention. Now, observe that, because type $i$ is willing to trade $\left(q_{i}-q_{i-1}, t_{i}-t_{i-1}\right)$ in addition to $\left(q_{i-1}, t_{i-1}\right)$, each bracketed term in $(2)$ cannot exceed $\left[\tau_{i}\left(q_{i-1}, t_{i-1}\right)-\bar{c}_{i}\right]\left(q_{i}-q_{i-1}\right)$. Thus, to prove that the entrant's expected profit is nonpositive, we only need to show that

For each $i, \tau_{i}\left(q_{i-1}, t_{i-1}\right) \leq \bar{c}_{i}$.

To establish these inequalities, we first show that $\left(q_{i-1}, t_{i-1}\right)$ has to lie in the nonnegative orthant, below the indifference curve of type $i$ that goes through the origin. As illustrated in Figure 1, the weak concavity of the indifference curve of type $i$ that goes through $\left(q_{i-1}, t_{i-1}\right)$, coupled with Assumption 1, then implies $\tau_{i}\left(q_{i-1}, t_{i-1}\right) \leq \tau_{i}(0,0)$, from which (3) follows according to Property NE. Although seemingly innocuous, Assumption 1 plays an important role in the proof. Indeed, as we show in Appendix D, when it fails to hold one can build examples in which entry is profitable in spite of Property NE being satisfied. ${ }^{3}$

Overall, the main insight of Theorem 1 is that the upper-tail conditional expectations of unit costs play a key role when evaluating whether an inactive market is entry-proof. In that respect, everything happens as if information were complete, with each $c_{i}$ turned into $\bar{c}_{i}$. It should be noted that Property NE does not rule out gains from trade, in the usual first-best sense of the term. Indeed, it may well be that $\bar{c}_{i} \geq \tau_{i}(0,0)>c_{i}$ for any type $i<I .{ }^{4}$ Rather, as the proof of Theorem 1 makes clear, what Property NE rules out are gains from trade on any marginal quantity $q_{i}-q_{i-1}$, which is all that matters for entry to be unprofitable in the second-best case where the buyer's type is unknown to the entrant.

\footnotetext{
${ }^{3}$ The intuition is that the marginal rate of substitution can then take values higher than $\tau_{i}(0,0)$ in the relevant area drawn in Figure 1. Relatedly, a strengthening of Assumption 1 into $\tau_{i}(q, t) \leq \bar{c}_{i}$ for all $(q, t)$ such that $t \geq 0$ and $u_{i}(q, t) \geq u_{i}(0,0)$ still allows to prove Theorem 1 , even when preferences are not convex.

${ }^{4}$ Of course, this cannot be true of the last type $I$, for which $c_{I}=\bar{c}_{I}$ holds by definition.
} 


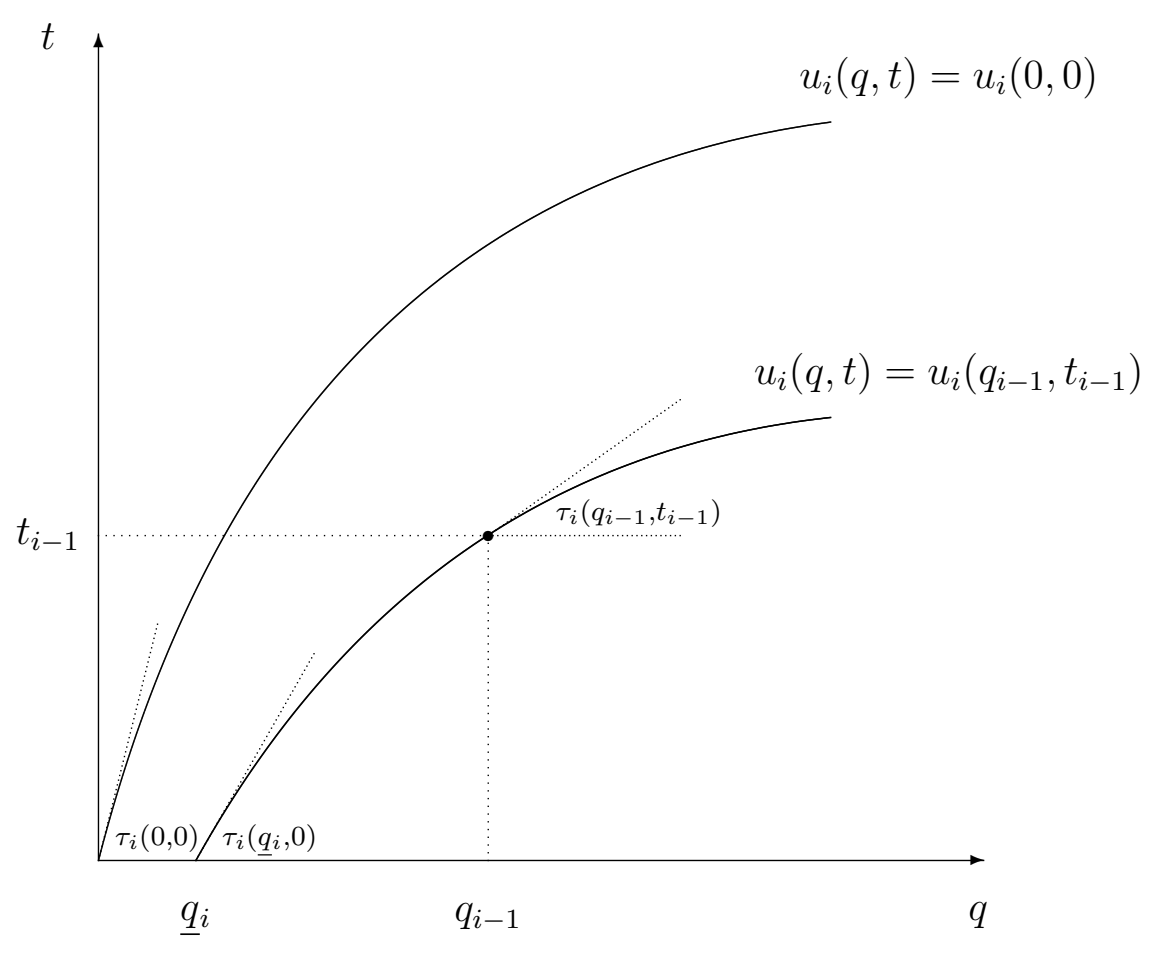

Figure 1 A graphical illustration of (3).

One reason why the generality of the role of upper-tail conditional expectations of unit costs seems to have been overlooked in the existing literature is that, although they determine whether a monopolist's expected profit is positive or not, their values have no impact on the solution to the monopoly problem. To illustrate this point, let us apply Wilson's (1993) demand-profile approach to the simple case of differentiable quasilinear utilities,

$$
u_{i}(q, t)=U_{i}(q)-t
$$

Given a tariff $T(q)$, the single-crossing condition allows to define a threshold type $i(q)$ as the first type purchasing at least the quantity $q$. As shown in Appendix E, the resulting expected profit can be rewritten as

$$
\int_{0}^{\infty}\left(\sum_{j \geq i(q)} m_{j}\right)\left[U_{i(q)}^{\prime}(q)-\bar{c}_{i(q)}\right] \mathrm{d} q .
$$

Thus the upper-tail conditional expectations of unit costs do indeed determine the sign of the expected profit earned on each marginal quantity $\mathrm{d} q$. On the other hand, the solution to the monopoly's problem is, under some additional assumptions, given by

$$
U_{i}^{\prime}\left(q_{i}\right)=c_{i}+\frac{\sum_{j>i} m_{j}}{m_{i}}\left[U_{i+1}^{\prime}\left(q_{i}\right)-U_{i}^{\prime}\left(q_{i}\right)\right]
$$

from which the upper-tail conditional expectations of unit costs have disappeared. 


\section{Market Breakdown}

We have so far characterized when an inactive market is entry-proof, that is, when no seller can enter the market and earn a strictly positive expected profit no matter the buyer's best response. The existing literature instead focuses on characterizing market breakdown, defined as a situation in which any trade that the buyer is willing to make is loss-making, even when her best response is favorable to the entrant. We here provide an additional result for this stronger concept. Note that, in any case, Property NE remains necessary. However, other assumptions need to be reinforced to obtain sufficiency. ${ }^{5}$

The first difficulty is that one may design menus of contracts for which the buyer has multiple best responses, some of which may be more favorable to the entrant than others. This difficulty can be overcome by requiring types to be ordered according to the strict single-crossing condition (Milgrom and Shannon (1994)): ${ }^{6}$

For all $i<j, q<q^{\prime}, t$, and $t^{\prime}, u_{i}(q, t) \leq u_{i}\left(q^{\prime}, t^{\prime}\right)$ implies $u_{j}(q, t)<u_{j}\left(q^{\prime}, t^{\prime}\right)$.

The following example illustrates that weakly profitable entry can take place when strict single crossing does not hold, even though Property NE is satisfied.

Example 1 Consider a two-type economy in which both types have the same preferences represented by $u(q, t)=q-q^{2}-t$, but different costs such that $c_{1}<1<\bar{c}_{1}<c_{2}$; thus Property NE is satisfied. Both types are indifferent between not trading and trading the quantity $1-c_{1}$ at unit price $c_{1}$. By offering this contract, an entrant may then earn zero expected profit if type 1 accepts, and type 2 chooses not to trade with him.

Even under strict single crossing, it is possible that the expected profit be zero on each marginal quantity $q_{i}-q_{i-1}$. A simple and natural way to avoid this situation is to assume that the buyer's preferences are strictly convex. Indeed, under this additional assumption, inequalities (3) together with the downward local constraints $u_{i}\left(q_{i}, t_{i}\right) \geq u_{i}\left(q_{i-1}, t_{i-1}\right)$ directly imply that the expected profit from each marginal quantity $q_{i}-q_{i-1}$ is strictly negative whenever $q_{i-1}<q_{i}$. The following example illustrates that weakly profitable entry can take place when strict quasiconcavity does not hold, even though strict single crossing holds and Property NE is satisfied.

Example 2 Consider, in line with Samuelson (1984), Myerson (1985), and Attar, Mariotti, and Salanié (2011), an Akerlof (1970) economy in which a divisible good is traded, subject

\footnotetext{
${ }^{5} \mathrm{~A}$ natural idea is to simply reinforce Property NE, into $\tau_{i}(0,0)<\bar{c}_{i}$ for any type $i$. Whereas this strong property is sufficient for market breakdown, it is nevertheless not necessary.

${ }^{6}$ See Footnote 13 for the corresponding modification of the proof of Theorem 1.
} 
to a capacity constraint normalized to 1 . Each type $i$ has linear preferences represented by $u_{i}(q, t)=\bar{c}_{i} q-t$, where $\bar{c}_{i}$ is strictly increasing in $i$. Under this highly nongeneric assumption, strict single crossing holds and Property NE is satisfied with equality for each type. Suppose now that the entrant offers a menu of contracts $\left\{\left(q_{1}, t_{1}\right), \ldots,\left(q_{I}, t_{I}\right)\right\}$ with strictly positive quantities $q_{i}$ that are nondecreasing in $i$, and transfers $t_{i}$ such that $t_{i}-t_{i-1}=\bar{c}_{i}\left(q_{i}-q_{i-1}\right)$. Any such allocation yields zero expected profit for the entrant and exhibits strict gains from trade for types $i>1$. The intuition is that Property NE rules out gains from trade for any type $i$ on the marginal quantity $q_{i}-q_{i-1}$, but not necessarily, for $i>1$, on the inframarginal quantities $q_{j}-q_{j-1}, j<i$. Hence, whereas strictly profitable entry is ruled out by Theorem 1 , weakly profitable entry is possible, in many different ways, if type 1 accepts to trade $\left(q_{1}, \bar{c}_{1} q_{1}\right)$, even though she could as well not trade.

Summarizing, we obtain the following result.

Corollary 1 Suppose that, for each $i, u_{i}$ is strictly quasiconcave, and that types are ordered according to the strict single-crossing condition. Then there is market breakdown if and only if Property NE is satisfied.

Mailath and Nöldeke (2008) obtain a related result for an economy in which the buyer has quadratic quasilinear preferences, as in Glosten (1989) or Biais, Martimort, and Rochet (2000). However, they focus on competitive pricing, defined as a situation in which each quantity traded must yield zero expected profit, ruling out cross-subsidies between contracts. This is an important restriction: indeed, as Example 2 illustrates, the best pricing strategy for the entrant may not be competitive in this sense, because what matters is not the absolute profit earned on each quantity $q_{i}$, but rather the marginal profit earned on each marginal quantity $q_{i}-q_{i-1}$.

Hendren (2013) studies a Rothschild and Stiglitz (1976) insurance economy, and his Theorem 1 is the analogue of Corollary 1 in this particular setting. As emphasized by the author, an implication of Property NE is that the highest-risk type $I$ must not be willing to purchase coverage at the actuarially fair rate $c_{I}$. Given that her preferences have an expected-utility representation, this is possible only if $c_{I}=1$, that is, if type $I$ incurs a loss with probability 1 . In that case, type $I$ 's preferences are no longer strictly quasiconcave, and the above result becomes that all types except perhaps type $I$ are excluded from trade.

\section{When Is an Active Market Entry-Proof?}

A striking feature of Property NE is that we can also use it to characterize entry-proof active 
markets. We here focus on nonexclusive markets, in which a buyer can simultaneously trade with several sellers. On such markets, each seller aims at limiting the risk of attracting high-cost types buying large quantities, and to do so can use limit orders - that is, offers to sell at a given unit price up to a maximum quantity. Perhaps for this reason, limit orders are one of the main instruments used on financial markets, and especially so when the market is organized as a limit-order book (Glosten (1994)). For us, the important property that we shall exploit below is that, if sellers post collections of limit orders, or, equivalently, convex tariffs, the buyer faces a convex market tariff $T$, obtained by convolution of those tariffs. We will use Property NE to show that requiring such a tariff to be entry-proof singles out a unique budget-balanced allocation, the construction of which crucially hinges on upper-tail conditional expectations of unit costs.

Let us assume without further mention that the domain of $T$ is a compact interval containing 0 , with $T(0)=0$. Each type $i$ then selects her optimal quantity $q_{i}$ so as to maximize $u_{i}(q, T(q))$. We say in that case that the allocation $\left(q_{i}, T\left(q_{i}\right)\right)_{i=1}^{I}$ is implemented by $T$, and that it is budget-balanced if

$$
\sum_{i} m_{i}\left[T\left(q_{i}\right)-c_{i} q_{i}\right] \geq 0
$$

We shall assume that the utility functions $u_{i}$ are strictly quasiconcave and that types are ordered according to the strict single-crossing condition. Thus, given a convex $\operatorname{tariff} T$, each type $i$ has a unique optimal quantity $q_{i}$, which is nondecreasing in $i$.

Now, suppose an entrant can propose side trades to the buyer, in the form of a menu of contracts. We say that the tariff $T$ is entry-proof if there is no menu of contracts that yields the entrant a strictly positive expected profit no matter the buyer's best response, taking into account that the buyer is free to combine these contracts with the market tariff T. Our goal is to characterize the set of budget-balanced allocations that are implementable by entry-proof convex market tariffs.

Let us first observe that, from the entrant's viewpoint, everything happens as if he faced modified types with indirect utility functions

$$
u_{i}^{T}\left(q^{\prime}, t^{\prime}\right) \equiv \max \left\{u_{i}\left(q+q^{\prime}, T(q)+t^{\prime}\right): q \geq 0\right\}
$$

reflecting that the buyer is free to combine any contract $\left(q^{\prime}, t^{\prime}\right)$ offered by the entrant with the market tariff $T$. In particular, $u_{i}^{T}(0,0)$ represents type $i$ 's utility when she only trades on the market and not with the entrant, and thus defines the relevant individual-rationality constraint for type $i$ from the entrant's viewpoint. 
A key observation is that, because the market tariff $T$ is convex and the primitive utility functions $u_{i}(q, t)$ are strictly quasiconcave in $(q, t)$ and strictly decreasing in $t$, the indirect utility functions $u_{i}^{T}\left(q^{\prime}, t^{\prime}\right)$ are weakly quasiconcave in $\left(q^{\prime}, t^{\prime}\right)$ and strictly decreasing in $t^{\prime}$. Hence we can define the marginal rates of substitution $\tau_{i}^{T}\left(q^{\prime}, t^{\prime}\right)$ associated to them exactly as we did in Section 2 for the primitive utility functions. Furthermore, because the primitive types are ordered according to the strict single-crossing condition, the modified types are ordered according to the single-crossing condition. ${ }^{7}$

These properties suggest using Theorem 1 to characterize the set of budget-balanced allocations that are implementable by entry-proof convex tariffs. To do so, we only need to ensure that Assumption 1 holds for the marginal rates of substitution $\tau_{i}^{T}\left(q^{\prime}, 0\right)$. A convenient way to proceed is to impose that each type's family of primitive indifference curves satisfy a slightly stronger "fanning-out" property than that embedded in Assumption 1.

Assumption 2 For all $i$ and $t, \tau_{i}(q, t)$ is weakly decreasing with respect to $q$.

Assumption 2 is quite weak, and notably holds in the illustrative examples provided in Appendix A. The following result, for which a formal proof is provided in Appendix B, yields the desired implication.

Lemma 1 Suppose that $u_{i}(q, t)$ is strictly quasiconcave in $(q, t)$, and let $T$ be a convex tariff. Then Assumption 1 holds for $\tau_{i}^{T}\left(q^{\prime}, 0\right)$ if Assumption 2 holds for $\tau_{i}(q, t)$.

An immediate consequence of Theorem 1 is thus that a tariff $T$ is entry-proof if and only if the following holds:

$$
\text { For each } i, \tau_{i}^{T}(0,0) \leq \bar{c}_{i} \text {. }
$$

To see what this condition entails, observe that, according to $(7), \tau_{i}^{T}(0,0)$ is the supremum of the set of prices $p$ such that

$u_{i}\left(q_{i}, T\left(q_{i}\right)\right)=u_{i}^{T}(0,0)<\max \left\{u_{i}^{T}\left(q^{\prime}, p q^{\prime}\right): q^{\prime} \geq 0\right\}=\max \left\{u_{i}\left(q+q^{\prime}, T(q)+p q^{\prime}\right): q, q^{\prime} \geq 0\right\}$

Thus, according to (8), we have

For each $i, u_{i}\left(q_{i}, T\left(q_{i}\right)\right) \geq \max \left\{u_{i}\left(q+q^{\prime}, T(q)+\bar{c}_{i} q^{\prime}\right): q, q^{\prime} \geq 0\right\}$.

In particular, letting $q=q_{i-1}$ and $q^{\prime}=q_{i}-q_{i-1}$ yields $T\left(q_{i}\right)-T\left(q_{i-1}\right) \leq \bar{c}_{i}\left(q_{i}-q_{i-1}\right)$ for all

\footnotetext{
${ }^{7}$ See Attar, Mariotti, and Salanié (2016b, Appendix) for a proof of these observations.
} 
$i$, with $q_{0} \equiv 0$ by convention. Rewriting the expected profit (6) as in (2), and imposing that the allocation $\left(q_{i}, T\left(q_{i}\right)\right)_{i=1}^{I}$ be budget-balanced, we obtain

$$
\text { For each } i, T\left(q_{i}\right)-T\left(q_{i-1}\right)=\bar{c}_{i}\left(q_{i}-q_{i-1}\right) \text {. }
$$

To conclude, observe first that, because $T$ is convex, we have

$$
\text { For each } i, T\left(q_{i}\right)-T\left(q_{i-1}\right) \leq \partial^{-} T\left(q_{i}\right)\left(q_{i}-q_{i-1}\right)
$$

Moreover, we must have

$$
\text { For each } i \text { such that } q_{i}>0, \partial^{-} T\left(q_{i}\right) \leq \tau_{i}^{T}(0,0) \text {, }
$$

for, otherwise, some type $i$ would purchase a quantity strictly smaller than $q_{i}$ from the market. ${ }^{8}$ Given (9), we conclude that the inequalities (8) and (10)-(11) hold as equalities, so that $\tau_{i}^{T}(0,0)=\bar{c}_{i}=\partial^{-} T\left(q_{i}\right)=\left[T\left(q_{i}\right)-T\left(q_{i-1}\right)\right] /\left(q_{i}-q_{i-1}\right)$ for all $i$ such that $q_{i}>q_{i-1}$. Thus, as $T$ is convex and $u_{i}$ is strictly quasiconcave for all $i$, there exists a unique candidate for a budget-balanced allocation that is implementable by an entry-proof convex tariff, namely, the allocation recursively defined by $\left(q_{0}^{*}, T^{*}\left(q_{0}^{*}\right)\right) \equiv(0,0)$ and, for each $i$,

$$
\begin{aligned}
q_{i}^{*} & \equiv q_{i-1}^{*}+\arg \max \left\{u_{i}\left(q_{i-1}^{*}+q^{\prime}, T^{*}\left(q_{i-1}^{*}\right)+\bar{c}_{i} q^{\prime}\right): q^{\prime} \geq 0\right\}, \\
T^{*}\left(q_{i}^{*}\right) & \equiv T^{*}\left(q_{i-1}^{*}\right)+\bar{c}_{i}\left(q_{i}^{*}-q_{i-1}^{*}\right) .
\end{aligned}
$$

Following Attar, Mariotti, and Salanié (2014, 2016a), we label the allocation $\left(q_{i}^{*}, T^{*}\left(q_{i}^{*}\right)\right)_{i=1}^{I}$, which was originally introduced in different contexts by Jaynes (1978), Hellwig (1988), and Glosten (1994), the JHG allocation. Notice that it is well defined, for instance, when the following Inada condition is assumed:

For all $i,(q, t)$, and $p>0, \arg \max \left\{u_{i}\left(q+q^{\prime}, t+p q^{\prime}\right): q^{\prime} \geq 0\right\}<\infty$.

The JHG allocation $\left(q_{i}^{*}, T^{*}\left(q_{i}^{*}\right)\right)_{i=1}^{I}$ is such that, if each type $i$ selects $\left(q_{i}^{*}, T\left(q_{i}^{*}\right)\right)$, then the resulting expected profit is exactly zero: indeed, each marginal quantity $q_{i}^{*}-q_{i-1}^{*}$ is priced at the expected $\operatorname{cost} \bar{c}_{i}$ of serving those types who buy it. The JHG allocation is easily shown to be incentive-compatible: the downward local constraints hold by construction and, because the quantities $q_{i}^{*}$ are nondecreasing in $i$, global incentive compatibility follows. Finally, there exists an essentially unique convex tariff implementing the $\mathrm{JHG}$ allocation, ${ }^{9}$ namely, the $J H G$ tariff defined by

$$
T^{*}(q) \equiv T^{*}\left(q_{i-1}^{*}\right)+\bar{c}_{i}\left(q-q_{i-1}^{*}\right) \text { if } q_{i-1}^{*} \leq q \leq q_{i}^{*} .
$$

\footnotetext{
${ }^{8}$ See Lemma 1 for a formal proof of this statement.

${ }^{9} \mathrm{We}$ may variously extend the tariff (15) beyond $q_{I}^{*}$, but such changes are inessential.
} 
Thus this tariff consists of a sequence of segments with slopes $\bar{c}_{i}$, and an upward kink at each quantity $q_{i}^{*}>0$ whenever $\bar{c}_{i}$ is strictly increasing in $i{ }^{10}$ By construction, we have $\tau_{i}^{T^{*}}(0,0)=\tau_{i}(0,0) \leq \bar{c}_{i}$ for all $i$ such that $q_{i}^{*}=0$ and $\tau_{i}^{T^{*}}(0,0)=\partial^{-} T\left(q_{i}^{*}, T^{*}\left(q_{i}^{*}\right)\right)=\bar{c}_{i}$ for all $i$ such that $q_{i}^{*}>0$, so that we can conclude from Theorem 1 that the JHG tariff is entry-proof. Summarizing, the following result holds.

Corollary 2 Suppose that, for each $i, u_{i}$ is strictly quasiconcave, that the Inada condition (14) and Assumption 2 hold, and that types are ordered according to the strict single-crossing condition. Then the JHG allocation (12)-(13) is the unique budget-balanced allocation that is implementable by an entry-proof convex tariff, and this tariff is the JHG tariff.

The generality of this result deserves special emphasis. First, the strict single-crossing condition can be relaxed, provided one focuses on allocations with nondecreasing quantities. Next, the buyer's preferences need not be quasilinear, unlike in Glosten's (1994) original analysis. This paves the way for applications to health- or life-insurance markets, which are typically nonexclusive, and where wealth effects are likely to be relevant. By contrast, the assumption that the market tariff is convex plays an important role in our analysis by ensuring that the modified types are ordered according to the single-crossing condition, and seems difficult to relax. ${ }^{11}$

Our analysis suggests new empirical tests of adverse selection on nonexclusive markets. To fix ideas, let us consider the case of a binary-loss insurance economy, and suppose that we are given a survey of consumers $n=1, \ldots, N$, which provides information about each consumer's aggregate amount of coverage $Q_{n}$, the aggregate premium $T_{n}$ she pays in return, and her eventual loss $L_{n} \in\{0,1\}$. Using the observations on coverage choices choices $\left(Q_{n}\right)_{n=1}^{N}$ and premia $\left(T_{n}\right)_{n=1}^{N}$, we can first nonparametrically estimate the marginal price schedule $p=\partial^{-} T{ }^{12}$ Equipped with an estimator $\hat{p}^{N}$ and with observations on losses $\left(L_{n}\right)_{n=1}^{N}$, we can then proceed to test whether these observations are consistent with the JHG tariff. To do so, we need only compare, for each $q$, the estimated marginal price $\hat{p}^{N}(q)$ with the empirical loss frequency

$$
\hat{\bar{c}}^{N}(q) \equiv \frac{\sum_{n} 1_{\left\{Q_{n} \geq q, L_{n}=1\right\}}}{\sum_{n} 1_{\left\{Q_{n} \geq q\right\}}}
$$

\footnotetext{
${ }^{10}$ In the case of the limit-order book, this corresponds to a family of limit orders with quantities $q_{i}^{*}-q_{i-1}^{*}$ and unit prices $\bar{c}_{i}$.

${ }^{11}$ Attar, Mariotti, and Salanié (2016a) prove a result similar to Corollary 2 for general market tariffs, but their analysis is limited to the two-type case.

${ }^{12} \mathrm{~A}$ relevant statistical model could be a nonparametric regression $T_{n}=T\left(Q_{n}\right)+\varepsilon_{n}$ with one-sided errors $\varepsilon_{n}$, reflecting that the buyers may make errors in combining the sellers' offers into the market tariff $T$.
} 
of those consumers whose aggregate coverage is at least $q$. Note that prices play a crucial role in this empirical procedure. This contrasts with standard tests of the positive-correlation property, which only rely on the observation that, under adverse selection, there should be a positive correlation between the coverage purchased by a consumer and her risk (Chiappori and Salanié (2000)). In any case, estimates of upper-tail conditional expectations of unit costs are likely to play a crucial role for tests of adverse selection besides the case of inactive markets studied by Hendren (2013). 


\section{Appendix A: Illustrative Examples}

The following examples for the buyer's preferences illustrate the range of our model.

Quasilinear Utility We may first suppose, as in the models of trade on financial markets studied by Glosten (1994) and Mailath and Nöldeke (2008), that each type $i$ ' preferences are quasilinear,

$$
u_{i}(q, t)=U_{i}(q)-t
$$

for some concave utility function $U_{i}$. The single-crossing condition holds if, for each $q$, $\partial^{+} U_{i}(q)$ is nondecreasing in $i$, and the concavity of $U_{i}$ ensures that Assumption 1 holds.

Expected Utility Consider next a Rothschild and Stiglitz (1976) insurance economy. The buyer has initial wealth $w_{0}$ and faces the risk of a loss $l$ with a probability $c_{i}$ that defines her type. Each type $i$ 's preferences over coverage-premium pairs $(q, t)$ have an expected-utility representation,

$$
u_{i}(q, t)=c_{i} u\left(w_{0}-l+q-t\right)+\left(1-c_{i}\right) u\left(w_{0}-t\right)
$$

for some strictly increasing and strictly concave von Neumann-Morgenstern utility function $u$. The single-crossing condition holds if $c_{i}$ is nondecreasing in $i$, and the concavity of $u$ ensures that Assumption 1 holds.

We can modify this example to allow for multiple loss levels if we focus on coinsurance contracts requiring that a fraction $q$ of the loss be covered for a premium $t$. The buyer has initial wealth $w_{0}$ and faces the risk of a loss $l$ distributed according to a density $f_{i}$ that defines her type. Each type $i$ 's preferences then have the following representation:

$$
u_{i}(q, t) \equiv \int u\left(w_{0}-(1-q) l-t\right) f_{i}(l) \mathrm{d} l .
$$

The single-crossing condition holds whenever the densities $f_{i}$ are increasing in the monotonelikelihood ratio order, that is, whenever higher types are relatively more likely to incur large losses than lower types are (Attar, Mariotti, and Salanié (2016a, Appendix B)). This, in turn, implies that the former are more costly to serve than the latter, as required.

Rank-Dependent Expected Utility Consider again a Rothschild and Stiglitz (1976) insurance economy but, following Quiggin (1982), suppose that each type $i$ 's preferences over coverage-premium pairs $(q, t)$ have a rank-dependent expected-utility representation,

$$
u_{i}(q, t)=\left[w(1)-w\left(1-c_{i}\right)\right] u\left(w_{0}-l+q-t\right)+w\left(1-c_{i}\right) u\left(w_{0}-t\right)
$$


for some strictly increasing and strictly concave von Neumann-Morgenstern utility function $u$ and some strictly increasing weighting function $w$ such that $w(0)=0$ and $w(1)=1$. Because $w$ is strictly increasing, the single-crossing condition holds if $c_{i}$ is nondecreasing in $i$, and the concavity of $u$ ensures that Assumption 1 holds.

Robust Control Our framework also encompasses ambiguity. Consider again a Rothschild and Stiglitz (1976) insurance economy but, following Hansen and Sargent (2007), suppose that each type $i$ recognizes that the true probability distribution over outcomes $\tilde{\mathbf{c}}_{i} \equiv\left(\tilde{c}_{i}, 1-\tilde{c}_{i}\right)$ is uncertain and may differ from $\mathbf{c}_{i} \equiv\left(c_{i}, 1-c_{i}\right)$. Then type $i$ 's preferences over coveragepremium pairs $(q, t)$ have a robust-control representation,

$$
u_{i}(q, t)=\min _{\tilde{\mathbf{c}}_{i}}\left\{\tilde{c}_{i} u\left(w_{0}-l+q-t\right)+\left(1-\tilde{c}_{i}\right) u\left(w_{0}-t\right)+\alpha e\left(\tilde{\mathbf{c}}_{i}, \mathbf{c}_{i}\right)\right\}
$$

for some strictly increasing and strictly concave von Neumann-Morgenstern utility function $u$, where $e\left(\tilde{\mathbf{c}}_{i}, \mathbf{c}_{i}\right)$ is the relative entropy function that penalizes distortions from $\mathbf{c}_{i}$,

$$
e\left(\tilde{\mathbf{c}}_{i}, \mathbf{c}_{i}\right) \equiv \tilde{c}_{i} \log _{2}\left(\frac{\tilde{c}_{i}}{c_{i}}\right)+\left(1-\tilde{c}_{i}\right) \log _{2}\left(\frac{1-\tilde{c}_{i}}{1-c_{i}}\right) .
$$

As $u_{i}$ is a minimum of concave functions, it is itself concave. For each $(q, t)$, let us denote by $\tilde{\mathbf{c}}_{i}(q, t)=\left(\tilde{c}_{i}(q, t), 1-\tilde{c}_{i}(q, t)\right)$ the unique solution to the minimization problem that defines $u_{i}(q, t)$. Taking first-order conditions yields

$$
\frac{1-\tilde{c}_{i}(q, t)}{\tilde{c}_{i}(q, t)}=\frac{1-c_{i}}{c_{i}} 2^{u\left(w_{0}-l+q-t\right)-u\left(w_{0}-t\right)} .
$$

Thus, for each $(q, t), \tilde{c}_{i}(q, t)$ and $c_{i}$ are comonotonic in $i$, and $\tilde{c}_{i}(q, t)$ is strictly decreasing in $q$ for all $t$. Assuming that $u$ is differentiable, we can apply the envelope theorem to derive the marginal rate of substitution of $u_{i}$,

$$
\tau_{i}(q, t)=\left[1+\frac{1-\tilde{c}_{i}(q, t)}{\tilde{c}_{i}(q, t)} \frac{u^{\prime}\left(w_{0}-t\right)}{u^{\prime}\left(w_{0}-l+q-t\right)}\right]^{-1} .
$$

Hence, because $\tilde{c}_{i}(q, t)$ and $c_{i}$ are comonotonic in $i$, the single-crossing condition holds if $c_{i}$ is nondecreasing in $i$. Finally, the fact that $\tilde{c}_{i}(q, 0)$ is strictly decreasing in $q$ and the concavity of $u$ ensure that Assumption 1 holds.

Smooth Ambiguity Our framework also encompasses smooth ambiguity. Consider again a Rothschild and Stiglitz (1976) insurance economy but, following Klibanoff, Marinacci, and Mukerji (2005), suppose that each type $i$ 's preferences over coverage-premium pairs $(q, t)$ have a smooth-ambiguity-aversion representation,

$$
u_{i}(q, t)=\int \phi\left(c u\left(w_{0}-l+q-t\right)+(1-c) u\left(w_{0}-t\right)\right) f_{i}(c) \mathrm{d} c
$$


for some strictly increasing and strictly concave von Neumann-Morgenstern utility function $u$ and some strictly increasing and strictly concave function $\phi$ capturing ambiguity aversion regarding the true distribution over outcomes $\mathbf{c} \equiv(c, 1-c)$, the distribution of which is itself represented by a continuous density $f_{i}$ over $[0,1]$. As $\phi$ and $u$ are concave, so is $u_{i}$. Assuming that $\phi$ and $u$ are differentiable, with bounded derivatives over the relevant domain, we can express the marginal rate of substitution of $u_{i}$ as

$$
\begin{aligned}
\tau_{i}(q, t)=[1 & +\frac{u^{\prime}\left(w_{0}-t\right)}{u^{\prime}\left(w_{0}-l+q-t\right)} \\
& \left.\times \frac{\int \phi^{\prime}\left(c u\left(w_{0}-l+q-t\right)+(1-c) u\left(w_{0}-t\right)\right)(1-c) f_{i}(c) \mathrm{d} c}{\int \phi^{\prime}\left(c u\left(w_{0}-l+q-t\right)+(1-c) u\left(w_{0}-t\right)\right) c f_{i}(c) \mathrm{d} c}\right]^{-1} .
\end{aligned}
$$

We claim that the single-crossing condition holds if the densities $f_{i}$ are increasing in the monotone-likelihood-ratio order. To see this, observe that

$$
\frac{\int \phi^{\prime}\left(c u\left(w_{0}-l+q-t\right)+(1-c) u\left(w_{0}-t\right)\right)(1-c) f_{i}(c) \mathrm{d} c}{\int \phi^{\prime}\left(c u\left(w_{0}-l+q-t\right)+(1-c) u\left(w_{0}-t\right)\right) c f_{i}(c) \mathrm{d} c}=\frac{1}{\int c \mathrm{~d} G_{i}(c)}-1,
$$

where $G_{i}$ is a distribution with density

$$
g_{i}(c)=\frac{\phi^{\prime}\left(c u\left(w_{0}-l+q-t\right)+(1-c) u\left(w_{0}-t\right)\right) f_{i}(c)}{\int \phi^{\prime}\left(c u\left(w_{0}-l+q-t\right)+(1-c) u\left(w_{0}-t\right)\right) f_{i}(c) \mathrm{d} c}
$$

with respect to Lebesgue measure. As the densities $f_{i}$ are increasing in the monotonelikelihood ratio order, so are the densities $g_{i}$. This implies that the ratio $1 / \int c \mathrm{~d} G_{i}(c)$ is decreasing in $i$, which proves the claim given the above expression for $\tau_{i}(q, t)$. There remains to determine under which circumstances Assumption 1 holds. As above, we have

$$
\frac{\int \phi^{\prime}\left(c u\left(w_{0}-l+q\right)+(1-c) u\left(w_{0}\right)\right)(1-c) f_{i}(c) \mathrm{d} c}{\int \phi^{\prime}\left(c u\left(w_{0}-l+q\right)+(1-c) u\left(w_{0}\right)\right) c f_{i}(c) \mathrm{d} c}=\frac{1}{\int c \mathrm{~d} G_{i}(c \mid q)}-1,
$$

where, for each $q, G_{i}(\cdot \mid q)$ is a distribution with density

$$
g_{i}(c \mid q)=\frac{\phi^{\prime}\left(c u\left(w_{0}-l+q\right)+(1-c) u\left(w_{0}\right)\right) f_{i}(c)}{\int \phi^{\prime}\left(c u\left(w_{0}-l+q\right)+(1-c) u\left(w_{0}\right)\right) f_{i}(c) \mathrm{d} c}
$$

with respect to Lebesgue measure. We thus have

$$
\frac{g_{i}(c \mid 0)}{g_{i}(c \mid q)} \propto \frac{\phi^{\prime}\left(c u\left(w_{0}-l\right)+(1-c) u\left(w_{0}\right)\right)}{\phi^{\prime}\left(c u\left(w_{0}-l+q\right)+(1-c) u\left(w_{0}\right)\right)}
$$

up to multiplicative constants. Hence

$$
\begin{aligned}
\frac{\partial}{\partial c}\left[\frac{g_{i}(c \mid 0)}{g_{i}(c \mid q)}\right] \propto & -\frac{\phi^{\prime \prime}\left(c u\left(w_{0}-l\right)+(1-c) u\left(w_{0}\right)\right)}{\phi^{\prime}\left(c u\left(w_{0}-l\right)+(1-c) u\left(w_{0}\right)\right)}\left[u\left(w_{0}\right)-u\left(w_{0}-l\right)\right] \\
& +\frac{\phi^{\prime \prime}\left(c u\left(w_{0}-l+q\right)+(1-c) u\left(w_{0}\right)\right)}{\phi^{\prime}\left(c u\left(w_{0}-l+q\right)+(1-c) u\left(w_{0}\right)\right)}\left[u\left(w_{0}\right)-u\left(w_{0}-l+q\right)\right],
\end{aligned}
$$


which is strictly positive for $q>0$ if the function $\phi$ exhibits nonincreasing concavity in the sense that $-\phi^{\prime \prime} / \phi^{\prime}$ is nonincreasing. Under these circumstances, $g_{i}(c \mid 0)$ dominates $g_{i}(c \mid q)$ in the monotone-likelihood-ratio order and, as a result, $\int c \mathrm{~d} G_{i}(c \mid q)<\int c \mathrm{~d} G_{i}(c \mid 0)$. Combining this with the straightforward observation that $u^{\prime}\left(w_{0}-l+q\right)<u^{\prime}\left(w_{0}-l\right)$ by strict concavity of $u$, we obtain, using the above expression for $\tau_{i}(q, t)$, that $\tau_{i}(q, 0)<\tau_{i}(0,0)$ for all $q>0$, so that Assumption 1 holds.

It is easy to check that the slightly stronger Assumption 2 used in Section 5 holds in the above examples. Moreover, many other families of preferences, involving, for instance, first-order risk aversion (Segal and Spivak (1990)), also fit within our general framework.

\section{Appendix B: Proofs of the Main Results}

Proof of Theorem 1. The proof consists of three steps.

Step 1 We first formulate the entrant's problem. From the Revelation Principle, there is no loss of generality in letting the entrant offer a menu of contracts $\left\{\left(q_{1}, t_{1}\right), \ldots,\left(q_{I}, t_{I}\right)\right\}$ that is incentive-compatible,

\section{For all $i$ and $j, u_{i}\left(q_{i}, t_{i}\right) \geq u_{i}\left(q_{j}, t_{j}\right)$,}

and individually rational,

For each $i, u_{i}\left(q_{i}, t_{i}\right) \geq u_{i}(0,0)$.

We claim that, for any such menu, the buyer has a best response with quantities that are nondecreasing in her type. Indeed, if $i$ optimally trades $(q, t)$ and $j>i$ optimally trades $\left(q^{\prime}, t^{\prime}\right)$, then it must be that $u_{i}(q, t) \geq u_{i}\left(q^{\prime}, t^{\prime}\right)$ and $u_{j}\left(q^{\prime}, t^{\prime}\right) \geq u_{j}(q, t)$. Now, suppose that $q>q^{\prime}$. Because $i<j$ and $q>q^{\prime}$, applying single crossing to the first inequality yields $u_{j}(q, t) \geq u_{j}\left(q^{\prime}, t^{\prime}\right)$, which, along with the second inequality, implies $u_{j}(q, t)=u_{j}\left(q^{\prime}, t^{\prime}\right)$. So type $j$ could optimally trade $(q, t)$ as well. ${ }^{13}$ The same reasoning applies to any such pair $(i, j)$ for which quantities are decreasing, which proves the claim.

Because we want entry to be profitable no matter the buyer's best response, we are thus allowed to add the monotonicity constraint that quantities $q_{i}$ be nondecreasing in $i$ to the entrant's profit-maximization problem, as announced in the text. We can further relax this problem by focusing on the downward local constraints, that is, the downward local

\footnotetext{
${ }^{13}$ By contrast, the strict single-crossing condition allows to reach a contradiction at this point, so that all best responses exhibit nondecreasing quantities.
} 
incentive-compatibility constraints of types $i>1$ and the individual-rationality constraint of type $i=1$. The entrant's expected profit is thus bounded above by $\max \left\{\sum_{i} m_{i}\left(t_{i}-c_{i} q_{i}\right): q_{i}\right.$ is nondecreasing in $i$ and $u_{i}\left(q_{i}, t_{i}\right) \geq u_{i}\left(q_{i-1}, t_{i-1}\right)$ for all $\left.i\right\}$, with $\left(q_{0}, t_{0}\right) \equiv(0,0)$ by convention. We call $\mathcal{P}$ this relaxed problem.

Step 2 We now prove that we can focus in $\mathcal{P}$ on menus with nonnegative transfers. Indeed, suppose that a menu $\left\{\left(q_{1}, t_{1}\right), \ldots,\left(q_{I}, t_{I}\right)\right\}$ satisfies all the constraints in $\mathcal{P}$, and is such that at least one type makes a strictly negative payment. Let $i$ be the smallest such type. Then we can build a new menu by assigning $\left(q_{i-1}, t_{i-1}\right)$ to both types $i-1$ and $i$. Let us check that this new menu satisfies all the constraints in $\mathcal{P}$. First, because the original menu displays nondecreasing quantities, so does the new menu. Second, the downward local constraint for type $i$ is now an identity. Third, the downward local constraint for type $i+1$, if such type exists, now writes as $u_{i+1}\left(q_{i+1}, t_{i+1}\right) \geq u_{i+1}\left(q_{i-1}, t_{i-1}\right)$, which holds under single crossing because the initial menu satisfies $q_{i} \geq q_{i-1}, u_{i+1}\left(q_{i+1}, t_{i+1}\right) \geq u_{i+1}\left(q_{i}, t_{i}\right)$, and $u_{i}\left(q_{i}, t_{i}\right) \geq u_{i}\left(q_{i-1}, t_{i-1}\right)$. So all the constraints in $\mathcal{P}$ are satisfied by the new menu, as claimed. The resulting variation in expected profit is, up to multiplication by $m_{i}$,

$$
\left(t_{i-1}-c_{i} q_{i-1}\right)-\left(t_{i}-c_{i} q_{i}\right)=t_{i-1}-t_{i}+c_{i}\left(q_{i}-q_{i-1}\right),
$$

which is strictly positive as $t_{i-1} \geq 0>t_{i}$ by construction and $q_{i} \geq q_{i-1}$. It follows that the initial menu cannot be solution to $\mathcal{P}$. The entrant's expected profit is thus bounded above by the value of the problem $\mathcal{P}_{+}$obtained by adding to $\mathcal{P}$ the constraints $t_{i} \geq 0$ for all $i$.

Step 3 Fix a menu $\left\{\left(q_{1}, t_{1}\right), \ldots,\left(q_{I}, t_{I}\right)\right\}$ that satisfies all the constraints in $\mathcal{P}_{+}$and, for any type $i$, consider the trade $\left(q_{i-1}, t_{i-1}\right)$. For $i=1$, we clearly have $u_{i}\left(q_{i-1}, t_{i-1}\right) \geq u_{i}(0,0)$ as $\left(q_{0}, t_{0}\right)=(0,0)$. For $i>1$, we know that type $i-1$ weakly prefers $\left(q_{i-1}, t_{i-1}\right)$ to $(0,0)$. By single crossing, so does type $i$. Thus, in any case, we have $u_{i}\left(q_{i-1}, t_{i-1}\right) \geq u_{i}(0,0)$. Because $t_{i-1} \geq 0$, this shows that the indifference curve of type $i$ going through $\left(q_{i-1}, t_{i-1}\right)$ must cross the $q$-axis at some point $\left(\underline{q}_{i}, 0\right)$, with $\underline{q}_{i} \in\left[0, q_{i-1}\right]$. Under weak quasiconcavity, type $i$ 's marginal rate of substitution is nonincreasing with respect to the quantity purchased along this indifference curve. Therefore, $\tau_{i}\left(q_{i-1}, t_{i-1}\right) \leq \tau_{i}\left(\underline{q}_{i}, 0\right)$. Assumption 1 further implies $\tau_{i}\left(\underline{q}_{i}, 0\right) \leq \tau_{i}(0,0)$, and we can finally use Property NE to get (3). The argument in the text then shows that $\sum_{i} m_{i}\left(t_{i}-c_{i} q_{i}\right) \leq 0$, which implies that the value of $\mathcal{P}_{+}$is nonpositive. Hence the result.

Proof of Corollary 1. Suppose, by way of contradiction, that there is some trade, so that 
$q_{i}>q_{i-1}$ for some type $i$, and that the entrant earns zero expected profit. Then, as type $i$ 's preferences are strictly convex, and as $u_{i}\left(q_{i}, t_{i}\right) \geq u_{i}\left(q_{i-1}, t_{i-1}\right)$, inequality (3) implies $t_{i}-t_{i-1}-\bar{c}_{i}\left(q_{i}-q_{i-1}\right)<0$, so that the entrant's expected profit (2) is strictly negative, a contradiction. Hence the result.

Proof of Lemma 1. For the sake of clarity, we hereafter omit the index $i$. Let then $q^{T}\left(q^{\prime}\right)$ be the unique solution to the maximization problem in (7) for an arbitrary $q^{\prime}$, fixing $t^{\prime}=0$. The proof consists of three steps.

Step 1 We first claim that $q^{T}\left(q^{\prime}\right) \leq q^{T}(0)$ for all $q^{\prime}>0$. Suppose, by way of contradiction, that $q^{T}\left(q^{\prime}\right)>q^{T}(0)$ for some $q^{\prime}>0$, so that, in particular, $q^{T}\left(q^{\prime}\right)>0$. Notice first that

$$
\tau\left(q^{T}(0), T\left(q^{T}(0)\right)\right) \leq \partial^{+} T\left(q^{T}(0)\right)
$$

for, otherwise, type $i$ would purchase a quantity strictly higher than $q^{T}(0)$ on the market when she trades $(0,0)$ with the entrant. Similarly, letting $\tau^{-}\left(q^{T}\left(q^{\prime}\right)+q^{\prime}, T\left(q^{T}\left(q^{\prime}\right)\right)\right)$ be the slope of the buyer's indifference curve at the left of $\left(q^{T}\left(q^{\prime}\right)+q^{\prime}, T\left(q^{T}\left(q^{\prime}\right)\right)\right)$, it must be that

$$
\partial^{-} T\left(q^{T}\left(q^{\prime}\right)\right) \leq \tau^{-}\left(q^{T}\left(q^{\prime}\right)+q^{\prime}, T\left(q^{T}\left(q^{\prime}\right)\right)\right)
$$

for, otherwise, the buyer would purchase a quantity strictly smaller than $q^{T}\left(q^{\prime}\right)$ on the market when she trades $\left(q^{\prime}, 0\right)$ with the entrant. As $T$ is convex and $q^{T}\left(q^{\prime}\right)>q^{T}(0)$, we have $\partial^{-} T\left(q^{T}\left(q^{\prime}\right)\right) \geq \partial^{+} T\left(q^{T}(0)\right)$ and hence, according to (16)-(17),

$$
\tau^{-}\left(q^{T}\left(q^{\prime}\right)+q^{\prime}, T\left(q^{T}\left(q^{\prime}\right)\right)\right) \geq \tau\left(q^{T}(0), T\left(q^{T}(0)\right)\right) .
$$

Moreover, the buyer's indifference curve going through $\left(q^{T}\left(q^{\prime}\right)+q^{\prime}, T\left(q^{T}\left(q^{\prime}\right)\right)\right)$ must cross the horizontal line going through $\left(q^{T}(0), T\left(q^{T}(0)\right)\right)$ at some point $\left(\underline{q}, T\left(q^{T}(0)\right)\right)$ such that $q^{T}(0)<\underline{q}<q^{T}\left(q^{\prime}\right)+q^{\prime}$, and the strict quasiconcavity of $u$ implies

$$
\tau\left(\underline{q}, T\left(q^{T}(0)\right)\right)>\tau^{-}\left(q^{T}\left(q^{\prime}\right)+q^{\prime}, T\left(q^{T}\left(q^{\prime}\right)\right)\right)
$$

Combining (18) and (19) then yields

$$
\tau\left(\underline{q}, T\left(q^{T}(0)\right)\right)>\tau\left(q^{T}(0), T\left(q^{T}(0)\right)\right),
$$

which is impossible according to Assumption 2 because $\underline{q}>q^{T}(0)$. This proves the claim.

Step 2 We next claim that, for each $q^{\prime}$, the marginal rate of substitution of $u^{T}$ at $\left(q^{\prime}, 0\right)$ is given by

$$
\tau^{T}\left(q^{\prime}, 0\right)=\max \left\{\partial^{-} T\left(q^{T}\left(q^{\prime}\right)\right), \tau\left(q^{T}\left(q^{\prime}\right)+q^{\prime}, T\left(q^{T}\left(q^{\prime}\right)\right)\right)\right\}
$$


with $\partial^{-} T(0) \equiv-\infty$ by convention. By definition, $\tau^{T}\left(q^{\prime}, 0\right)$ is the supremum of the set of prices $p$ such that

$$
\begin{aligned}
u^{T}\left(q^{T}\left(q^{\prime}\right)+q^{\prime}, T\left(q^{T}\left(q^{\prime}\right)\right)\right) & <\max \left\{u^{T}\left(q^{\prime}+q^{\prime \prime}, p q^{\prime \prime}\right): q^{\prime \prime} \geq 0\right\} \\
& =\max \left\{\max \left\{u_{i}\left(q+q^{\prime}+q^{\prime \prime}, T(q)+p q^{\prime \prime}\right): q \geq 0\right\}: q^{\prime \prime} \geq 0\right\} \\
& =\max \left\{u_{i}\left(q+q^{\prime}+q^{\prime \prime}, T(q)+p q^{\prime \prime}\right): q, q^{\prime \prime} \geq 0\right\} \\
& =\max \left\{u_{i}\left(q^{\prime}+q^{\prime \prime \prime}, T \square T_{p}\left(q^{\prime \prime \prime}\right)\right): q^{\prime \prime \prime} \geq 0\right\},
\end{aligned}
$$

where $T_{p}$ is the linear tariff with slope $p$ and $T \square T_{p}\left(q^{\prime \prime \prime}\right) \equiv \min \left\{T(q)+T_{p}\left(q^{\prime \prime \prime}-q\right): q \in\left[0, q^{\prime \prime \prime}\right]\right\}$ is the infimal convolution of $T$ and $T_{p}$ (Rockafellar (1970, Theorem 5.4)). Note that the tariff $T \square T_{p}$ coincides with the tariff $T$ up to the first point $q_{p}$ such that $\partial^{+} T\left(q_{p}\right) \geq p$, and then is affine with slope $p$ from $q_{p}$ on. Thus $p$ satisfies (21) if and only if $p<\partial^{-} T\left(q^{T}\left(q^{\prime}\right)\right)$ or, if $\partial^{-} T\left(q^{T}\left(q^{\prime}\right)\right)<\tau\left(q^{T}\left(q^{\prime}\right)+q^{\prime}, T\left(q^{T}\left(q^{\prime}\right)\right)\right)$, if $p<\tau\left(q^{T}\left(q^{\prime}\right)+q^{\prime}, T\left(q^{T}\left(q^{\prime}\right)\right)\right)$. This proves the claim.

Step 3 We are now ready to complete the proof. Fix some $q^{\prime}>0$. We distinguish two cases. First, if $\tau\left(q^{T}\left(q^{\prime}\right)+q^{\prime}, T\left(q^{T}\left(q^{\prime}\right)\right)\right) \leq \partial^{-} T\left(q^{T}\left(q^{\prime}\right)\right)$, then, according to (20),

$$
\tau^{T}\left(q^{\prime}, 0\right)=\partial^{-} T\left(q^{T}\left(q^{\prime}\right)\right) \leq \max \left\{\partial^{-} T\left(q^{T}(0)\right), \tau\left(q^{T}(0), T\left(q^{T}(0)\right)\right)\right\}=\tau^{T}(0,0),
$$

where the inequality follows from the convexity of $T$ and from the fact that $q^{T}\left(q^{\prime}\right) \leq q^{T}(0)$. Second, if $\tau\left(q^{T}\left(q^{\prime}\right)+q^{\prime}, T\left(q^{T}\left(q^{\prime}\right)\right)\right)>\partial^{-} T\left(q^{T}\left(q^{\prime}\right)\right)$, then, according to (20),

$$
\tau^{T}\left(q^{\prime}, 0\right)=\tau\left(q^{T}\left(q^{\prime}\right)+q^{\prime}, T\left(q^{T}\left(q^{\prime}\right)\right)\right) \leq \partial^{+} T\left(q^{T}\left(q^{\prime}\right)\right)
$$

where the inequality parallels (16). If $q^{T}\left(q^{\prime}\right)<q^{T}(0)$, then $\partial^{+} T\left(q^{T}\left(q^{\prime}\right)\right) \leq \partial^{-} T\left(q^{T}(0)\right)$ by convexity of $T$, which implies $\tau^{T}\left(q^{\prime}, 0\right) \leq \tau^{T}(0,0)$ as above. Finally, if $q^{T}\left(q^{\prime}\right)=q^{T}(0)$, then $\tau\left(q^{T}(0), T\left(q^{T}(0)\right)\right) \geq \tau\left(q^{T}\left(q^{\prime}\right)+q^{\prime}, T\left(q^{T}\left(q^{\prime}\right)\right)\right)>\partial^{-} T\left(q^{T}\left(q^{\prime}\right)\right)=\partial^{-} T\left(q^{T}(0)\right)$ by Assumption 2 , so that

$$
\tau^{T}\left(q^{\prime}, 0\right)=\tau\left(q^{T}\left(q^{\prime}\right)+q^{\prime}, T\left(q^{T}\left(q^{\prime}\right)\right)\right) \leq \tau\left(q^{T}(0), T\left(q^{T}(0)\right)\right)=\tau^{T}(0,0)
$$

according to (20). The result follows.

\section{Appendix C: Arbitrary Distributions}

In this appendix, we extend Theorem 1 to arbitrary distributions of types with bounded support $\mathcal{I}$ over the real line. Denote by $i$ the buyer's type, and by $\mathbf{m}$ the corresponding distribution; m may be continuous, discrete, or mixed. It will sometimes be convenient to 
think of any point in $\overline{\mathcal{I}} \equiv[\min \mathcal{I}, \max \mathcal{I}]$ as a type, even if it does not belong to $\mathcal{I}$. We impose the same conditions on the utility functions $u_{i}(q, t)$ and on the upper-tail conditional expectations of unit $\operatorname{costs} \bar{c}_{i}^{\mathbf{m}} \equiv \mathbf{E}^{\mathbf{m}}\left[c_{j} \mid j \geq i\right]$ as in Section 2, and we moreover assume that $u_{i}(q, t)$ is jointly continuous in $(i, q, t)$ and that $c_{i}$ is continuous in $i$.

The proof that Property NE is necessarily satisfied if entry is unprofitable is exactly the same as in Section 3, and need not be repeated. There only remains to show that Property NE ensures entry proofness. The Taxation Principle tells us there is no loss of generality in letting the entrant offer a tariff specifying a transfer $T(q)$ to be paid as a function of the quantity $q$ demanded by the buyer (Hammond (1979), Guesnerie (1981), Rochet (1985)), with $T(0)=0$. We assume that the domain of $T$ is a compact set containing 0 , and that $T$ is bounded from below and lower semicontinuous. These minimal regularity conditions ensure that any type $i$ 's maximization problem

$$
\max \left\{u_{i}(q, T(q)): q \geq 0\right\}
$$

has a solution. The following result then holds.

Lemma 2 There exists for each $i$ a solution $q_{i}$ to (22) such that

(i) The mapping $i \mapsto q_{i}$ is nondecreasing.

(ii) The mapping $i \mapsto T\left(q_{i}\right)-c_{i} q_{i}$ is bounded from below and lower semicontinuous.

Proof. As in Step 1 of the proof of Theorem 1, the single-crossing condition ensures that we can select the buyer's best response in such a way that the mapping $i \mapsto q_{i}$ is nondecreasing. Hence (i). As for (ii), observe first that, because the $T$ has a compact domain and is bounded from below, the mapping $i \mapsto T\left(q_{i}\right)-c_{i} q_{i}$ is bounded from below no matter the buyer's best response. To show that the buyer's best response can be chosen in such a way that this mapping is lower semicontinuous, it is useful to fix a best response $i \mapsto q_{i}$ and some type $i_{0} \in \overline{\mathcal{I}}$, and then to distinguish two cases.

Case 1 Suppose first that $i \mapsto q_{i}$ is continuous at $i_{0}$. Then, as $T$ is lower semicontinuous and $c_{i}$ is continuous in $i$, we have $\liminf _{i \rightarrow i_{0}}\left\{T\left(q_{i}\right)-c_{i} q_{i}\right\} \geq T\left(q_{i_{0}}\right)-c_{i_{0}} q_{i_{0}}$.

Case 2 Suppose next that $i \mapsto q_{i}$ is discontinuous and left continuous at $i_{0}$. (The other types of jump discontinuities can be treated in a similar way.) Observe that, because the domain of $T$ is a compact set, it must include $q_{i_{0}}^{+}$; moreover, $T$ must be right continuous at $q_{i_{0}}^{+}$, for, otherwise, some type $i>i_{0}$ would be strictly better off purchasing $q_{i_{0}}^{+}$than $q_{i}$. Now, 
observe that type $i_{0}$ must be indifferent between the trades $\left(q_{i_{0}}, T\left(q_{i_{0}}\right)\right)$ and $\left(q_{i_{0}}^{+}, T\left(q_{i_{0}}^{+}\right)\right)$. Indeed, we clearly have $u_{i_{0}}\left(q_{i_{0}}, T\left(q_{i_{0}}\right)\right) \geq u_{i_{0}}\left(q_{i_{0}}^{+}, T\left(q_{i_{0}}^{+}\right)\right)$and, if we had $u_{i_{0}}\left(q_{i_{0}}, T\left(q_{i_{0}}\right)\right)>$ $u_{i_{0}}\left(q_{i_{0}}^{+}, T\left(q_{i_{0}}^{+}\right)\right)$, then, by continuity of $u_{i}$ in $i$, some type $i>i_{0}$ would be strictly better off purchasing $q_{i_{0}}$ than $q_{i}$, a contradiction. We can thus select the trade of type $i_{0}$ in such a way that $\liminf _{i \rightarrow i_{0}}\left\{T\left(q_{i}\right)-c_{i} q_{i}\right\} \geq T\left(q_{i_{0}}\right)-c_{i_{0}} q_{i_{0}}$. The result follows.

The next step of the analysis consists in checking that any distribution that satisfies Property NE can be weakly approximated by a sequence of discrete distributions that satisfy Property NE. Specifically, the following result holds.

Lemma 3 If $\mathbf{m}$ satisfies property NE, there exists a sequence of discrete distributions $\left(\mathbf{m}_{n}\right)_{n=1}^{\infty}$ that weakly converges to $\mathbf{m}$ and such that

$$
\text { For all } n \text { and } i, \bar{c}_{i}^{\mathbf{m}_{n}} \geq \bar{c}_{i}^{\mathbf{m}} \text {. }
$$

Proof. The proof is a simple adaptation of Hendren (2013, Supplementary Material, Lemma A.7), using the fact that $c_{i}$ is continuous in $i$ and that, as $\bar{c}_{i}^{\mathbf{m}}$ is nondecreasing in $i, c_{\max \mathcal{I}} \geq c_{i}$ for all $i$. Hendren's (2013) proof establishes that the sequence of cumulative distribution functions associated to the sequence $\left(\mathbf{m}_{n}\right)_{n=1}^{\infty}$ can be chosen so as to uniformly converge to the cumulative distribution function associated to $\mathbf{m}$. The result follows.

We are now ready to complete the proof of Theorem 1 for arbitrary distributions. Let $\mathbf{m}$ be a distribution that satisfies property NE. Fix a tariff $T$ as above and, for each $i$, a solution $q_{i}$ to (22) such that conditions (i)-(ii) in Lemma 2 hold. Lemma 3 implies that there exists a sequence of discrete distributions $\left(\mathbf{m}_{n}\right)_{n=1}^{\infty}$ that weakly converges to $\mathbf{m}$ and such that each $\mathbf{m}_{n}$ satisfies Property NE. Taking advantage of the fact that the mapping $i \mapsto q_{i}$ is nondecreasing, we can apply the version of Theorem 1 for discrete distributions provided in the main text to get

$$
\text { For each } n, \int\left[T\left(q_{i}\right)-c_{i} q_{i}\right] \mathbf{m}_{n}(\mathrm{~d} i) \leq 0 .
$$

Because the mapping $i \mapsto T\left(q_{i}\right)-c_{i} q_{i}$ is bounded from below and lowersemicontinuous, the weak convergence of the sequence $\left(\mathbf{m}_{n}\right)_{n=1}^{\infty}$ to $\mathbf{m}$ then yields, according to a corollary of the Portmanteau Theorem (Aliprantis and Border (2006, Theorem 15.5)),

$$
\int\left[T\left(q_{i}\right)-c_{i} q_{i}\right] \mathbf{m}(\mathrm{d} i) \leq \liminf _{n \rightarrow \infty}\left\{\int\left[T\left(q_{i}\right)-c_{i} q_{i}\right] \mathbf{m}_{n}(\mathrm{~d} i)\right\} \leq 0 .
$$

Hence, if the distribution $\mathbf{m}$ satisfies Property NE, no tariff can guarantee the entrant a strictly positive expected profit, which is the desired result. 


\section{Appendix D: On the Role of Assumption 1}

The following example illustrates the claim made in the main text that, when Assumption 1 does not hold, entry can be profitable in spite of Property NE being satisfied.

Example 3 Consider a two-type economy in which each type has preferences represented by $u_{i}(q, t)=(q+1)\left(\theta_{i} q-t\right)$, for $\theta_{2}>\theta_{1}>0$. These preferences are easily shown to be convex, with

$$
\tau_{i}(q, t)=\theta_{i}\left(1+\frac{q}{q+1}\right)-\frac{t}{q+1}
$$

so that the strict single-crossing condition holds. However, from $(23), \tau_{i}(q, 0)$ is strictly increasing in $q$, so that Assumption 1 does not hold. Now, fix quantities $q_{2}>q_{1}>0$. For some small $\eta>0$, consider an entrant offering a menu $\left\{\left(q_{1}, t_{1}\right),\left(q_{2}, t_{2}\right)\right\}$ such that

$$
t_{1} \equiv \theta_{1} q_{1}-\eta
$$

so that type 1 earns a small rent above $u_{1}(0,0)=0$, and

$$
t_{2} \equiv \theta_{2} q_{2}-\frac{q_{1}+1}{q_{2}+1}\left(\theta_{2} q_{1}-t_{1}\right)-\eta
$$

so that type 2 has a slight preference for $\left(q_{2}, t_{2}\right)$ over $\left(q_{1}, t_{1}\right)$. Each type has a unique best response, and the entrant's expected profit is $m_{1}\left(t_{1}-c_{1} q_{1}\right)+m_{2}\left(t_{2}-c_{2} q_{2}\right)$. To compute this expected profit, choose $\varepsilon>0$ and set up costs so that $\bar{c}_{1}=\theta_{1}+\varepsilon$ and $\bar{c}_{2}=\theta_{2}+\varepsilon$. Note that, from (23) again, Property NE is satisfied. According to (2), the entrant's expected profit can be rewritten as $t_{1}-\bar{c}_{1} q_{1}+m_{2}\left[t_{2}-t_{1}-\bar{c}_{2}\left(q_{2}-q_{1}\right)\right]$; this in turn simplifies into

$$
m_{1} m_{2}\left(c_{2}-c_{1}\right)\left(q_{2}-q_{1}\right) \frac{q_{1}}{q_{2}+1}-\varepsilon\left(m_{1} q_{1}+m_{2} q_{2}\right)-\eta\left(1+m_{2} \frac{q_{1}+1}{q_{2}+1}\right),
$$

which is strictly positive for arbitrary quantities $q_{2}>q_{1}>0$ whenever $\varepsilon$ and $\eta$ are small enough. This proves the claim. Notice that the entrant makes a profit when trading with type 1 and a loss when trading with type 2; but he also incurs an expected loss on the marginal quantity $q_{1}$, which he more than recoups on the marginal quantity $q_{2}-q_{1}$.

\section{Appendix E: Wilson's Demand Profile Approach}

Proof of (4)-(5). We throughout assume that the utility functions $U_{i}$ are strictly concave and differentiable and that the tariff $T$ is absolutely continuous. Thus the marginal price schedule $p=\partial T^{-}$is defined almost everywhere and, denoting by $q_{i}$ the quantity optimally 
purchased by type $i$ given the tariff $T$, we can rewrite the expected profit as

$$
\begin{aligned}
\sum_{i} m_{i}\left[T\left(q_{i}\right)-c_{i} q_{i}\right] & =\sum_{i} m_{i} \int_{0}^{q_{i}}\left[p(q)-c_{i}\right] \mathrm{d} q \\
& =\int_{0}^{\infty} \sum_{\left\{i: U_{i}^{\prime}(q) \geq p(q)\right\}} m_{i}\left[p(q)-c_{i}\right] \mathrm{d} q \\
& =\int_{0}^{\infty}\left(\sum_{\left\{i: U_{i}^{\prime}(q) \geq p(q)\right\}} m_{i}\right)\left\{p(q)-\mathbf{E}\left[c_{i} \mid U_{i}^{\prime}(q) \geq p(q)\right]\right\} \mathrm{d} q,
\end{aligned}
$$

where the second inequality follows from switching the sum and the integral signs, using the fact that type $i$, having already purchased the quantity $q-\mathrm{d} q$, is willing to purchase the marginal quantity $\mathrm{d} q$ if and only if $U_{i}^{\prime}(q) \geq \partial^{-} T(q)=p(q)$.

To derive (4) from (24), observe that, by single crossing, the set $\left\{i: U_{i}^{\prime}(q) \geq p(q)\right\}$ of types who purchase at least the quantity $q$ is of the form $\{i(q), \ldots, I\}$, or is empty if $q$ is too large, in which case $i(q) \equiv \infty$ by convention. We can always assume that $U_{i(q)}^{\prime}(q)=p(q)$. This is obvious if $T$ is differentiable at $q$. If $T$ has an upward kink at $q$, with types $i(q), \ldots, j(q)$ bunched at $q$, we can increase the expected profit by slightly increasing the tariff $T$ in such a way that the new tariff $\hat{T}$ satisfies $\partial^{-} \hat{T}(q)=U_{i(q)}^{\prime}(q)$ and $\partial^{+} \hat{T}(q)=U_{j(q)}^{\prime}(q)$, so that all these types remain bunched at $q$ but now pay a higher price; types above $j(q)$ may have to pay a slightly higher price, too. Hence (4).

To derive (5), observe that, if there is no bunching, so that $i\left(q_{i}\right)=i$ for all $i$, pointwise optimization of the integrand in (4) yields $\Delta_{i}(q) \geq 0$ for all $q \leq q_{i}$ and $\Delta_{i}(q)<0$ for all $q>q_{i}$, where

$$
\Delta_{i}(q) \equiv \sum_{j \geq i+1} m_{j} U_{i+1}^{\prime}(q)-\sum_{j \geq i+1} m_{j} c_{j}-\sum_{j \geq i} m_{j} U_{i}^{\prime}(q)+\sum_{j \geq i} m_{j} c_{j}
$$

This is continuous in $q$, so that $\Delta_{i}\left(q_{i}\right)=0$, which is (5). 


\section{References}

[1] Akerlof, G.A. (1970): "The Market for "Lemons": Quality Uncertainty and the Market Mechanism," Quarterly Journal of Economics, 84(3), 488-500.

[2] Aliprantis, C.D., and K.C. Border (2006): Infinite Dimensional Analysis: A Hitchhiker's Guide, Berlin, Heidelberg, New York: Springer.

[3] Attar, A., T. Mariotti, and F. Salanié (2011): "Nonexclusive Competition in the Market for Lemons," Econometrica, 79(6), 1869-1918.

[4] Attar, A., T. Mariotti, and F. Salanié (2014): "Nonexclusive Competition under Adverse Selection," Theoretical Economics, 9(1), 1-40.

[5] Attar, A., T. Mariotti, and F. Salanié (2016a): "Multiple Contracting in Insurance Markets," Toulouse School of Economics Working Paper $n^{\circ} 14-532$. Available at https://www.tse-fr.eu/fr/publications/multiple-contracting-insurance-markets.

[6] Attar, A., T. Mariotti, and F. Salanié (2016b): "On Competitive Nonlinear Pricing," Toulouse School of Economics Working Paper $n^{\circ}$ 16-737. Available at https://www.tsefr.eu/fr/publications/competitive-nonlinear-pricing.

[7] Biais, B., D. Martimort, and J.-C. Rochet (2000): "Competing Mechanisms in a Common Value Environment," Econometrica, 68(4), 799-837.

[8] Chiappori P.-A., and B. Salanié (2000): "Testing for Asymmetric Information in Insurance Markets," Journal of Political Economy, 108(1), 56-78.

[9] Glosten, L.R. (1989): "Insider Trading, Liquidity, and the Role of the Monopolist Specialist," Journal of Business, 62(2), 211-235.

[10] Glosten, L.R. (1994): "Is the Electronic Open Limit Order Book Inevitable?" Journal of Finance, 49(4), 1127-1161.

[11] Guesnerie, R. (1981): "On Taxation and Incentives: Further Reflections on the Limits to Redistribution," Discussion Paper, Institut für Gesellschafts- und Wirtschaftswissenschaften, Universität Bonn.

[12] Hammond, P.J. (1979): "Straightforward Individual Incentive Compatibility in Large Economies," Review of Economic Studies, 46(2), 263-282. 
[13] Hansen, L.P., and T.J. Sargent (2007): Robustness, Princeton: Princeton University Press.

[14] Hellwig, M.F. (1988): "A Note on the Specification of Interfirm Communication in Insurance Markets with Adverse Selection," Journal of Economic Theory, 46(1), 154163.

[15] Hendren, N. (2013): "Private Information and Insurance Rejections," Econometrica, 81(5), 1713-1762.

[16] Jaynes, G.D. (1978): "Equilibria in Monopolistically Competitive Insurance Markets," Journal of Economic Theory, 19(2), 394-422.

[17] Klibanoff, P., M. Marinacci, and S. Mukerji (2005): "A Smooth Model of Decision Making Under Ambiguity," Econometrica, 73(6), 1849-1892.

[18] Mailath, G., and G. Nöldeke (2008): "Does Competitive Pricing Cause Market Breakdown Under Extreme Adverse Selection?" Journal of Economic Theory, 140(1), 97-125.

[19] Milgrom, P., and C. Shannon (1994): "Monotone Comparative Statics," Econometrica, 62(1), 157-180.

[20] Myerson, R.B. (1985): "Analysis of Two Bargaining Problems with Incomplete Information," in Game-Theoretic Models of Bargaining, ed. by A.E. Roth. Cambridge, MA: Cambridge University Press, 115-147.

[21] Quiggin, J. (1982): "A Theory of Anticipated Utility," Journal of Economic Behavior and Organization, 3(4), 323-343.

[22] Rochet, J.-C. (1985): "The Taxation Principle and Multi-Time Hamilton-Jacobi Equations," Journal of Mathematical Economics, 14(2), 113-128.

[23] Rockafellar, R.T. (1970): Convex Analysis, Princeton, NJ: Princeton University Press.

[24] Rothschild, M., and J.E. Stiglitz (1976): "Equilibrium in Competitive Insurance Markets: An Essay on the Economics of Imperfect Information," Quarterly Journal of Economics, 90(4), 629-649.

[25] Samuelson, W. (1984): "Bargaining under Asymmetric Information," Econometrica, 52(4), 995-1005. 
[26] Segal, U., and A. Spivak (1990): "First Order Versus Second Order Risk Aversion," Journal of Economic Theory, 51(1), 111-125.

[27] Wilson, R.B. (1993): Nonlinear Pricing, Oxford: Oxford University Press. 